năng tạo bám dính sinh học bền vững giúp bảo vệ phức hợp tuỷ từ sự xâm nhập vi khuẩn và các tác nhân độc hại.

\section{KẾT LUÂN}

Với sự phát triển của xi măng calcium silicate có nhiều ưu điểm về đặc tính sinh học và cơ lý,

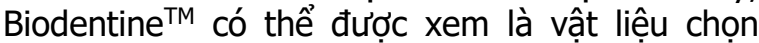
lựa tối ưu trong ứng dụng che tuỷ gián tiếp. Các nghiên cứu lâm sàng với số lượng ca lớn, theo dõi lâu dài là cần thiết.

\section{TÀl LIẸU THAM KHẢO}

1. Dhar V, Marghalani AA, Crystal Yo, et al. Use of vital pulp therapies in primary teeth with deep caries lesions. Pediatr Dent 2017;39(5):E146-E159.

2. Pradelle-Plasse. $N$, Tran $X V$, Colon $P$, Laurent P, Aubut V, About I, Goldberg M. Emerging trends in (bio) material research. Biocompatibility or Cytotoxic Effects of Dental Composites, 1st ed.; Coxmoor Publishing Company: Oxford, UK, 2009; pp.181-203

3. Koubi G, Colon P, Franquin JC, Hartmann A,
Gilles R, Faure MO, Lambert G. Clinical evaluation of the performance and safety of a new dentine substitute, Biodentine, in the restoration of posterior teeth - a prospective study. Clin Oral Invest 2013; 17: 243-249.

4. Kim JR, Nosrat A, Fouad AF. Interfacial characteristics of Biodentine and MTA with dentine in simulated body fluid. J Dent 2015;43:241-7.

5. About I, Murray PE, Franquin JC, et al. The effect of cavity restoration variables on odontoblast cell numbers and dental repair. J Dent 2001;29:109-17.

6. Nowicka A, Lipski M, Parafiniuk $M$, et al. Response of human dental pulp capped with Biodentine and mineral trioxide aggregate. J Endod 2013;39:743-7.

7. Tran XV, Gorin C, Willig C, Baroukh B, Pellat B, Decup F, Opsahl Vital $S_{\text {, Chaussain } C_{\text {, }}}$ Boukpessi T. Effect of a stepicalcium-silicatebased restorative cement on pulp repair. J Dent Res. 2012, 91, 1166-1171. 91:454-9.

8. Atmeh AR, Chong EZ, Richard G, Festy F, Watson TF; Dentin cement interfacial interaction: calcium silicates and polyalkenoates. Journal of Dental Research 2012; 91:454-9.

\title{
KHẢO SÁT MỐI LIÊN QUAN GIỮA ĐĂC ĐIỂM HÌNH ẢNH CộNG HƯỞNG TỪ VÀ MÔ BỆNH HỌC CỦA U MÀNG NÃO
}

\author{
Nguyễn Hữu Hoạt ${ }^{1}$, Đặng Đức Cảnh ${ }^{2}$, \\ Ngô Tuấn Minh ${ }^{2}$, Nguyễn Việt Dũng ${ }^{2}$, Nguyê̂n Xuân Khái ${ }^{3}$
}

\section{TÓM TẮT}

Muc đích: khảo sát mối liên quan giữa đặc điểm hình ảnh cộng hưởng từ (CHT) và tính chất lành tính/ác tính của u màng não (UMN). Đối tượng và phương pháp nghiên cứu: mô tả cắt ngang, trện 73 bênh nhân được chẩn đoán UMN, đã được phẩu thuật và có kết quả giải phẫu bệnh là UMN tại Bệnh viện Việt Đức và Bệnh viện Quân y 103 tử tháng $10 / 2020$ đến tháng $03 / 2021$. Kết quả: $56 / 73$ trường hợp là UMN lành tính, chiếm tỷ lệ 76,7\%. UMN không điển hình và ác tính chiếm tỷ lệ 23,3\%. 16/17 khối UMN độ II có hạn chế khuếch tán trên ảnh DWI và ADC, chiếm tỷ lệ $94,1 \%$, trong khi tỷ lệ này ở nhóm UMN độ I là $33,9 \%$. Sư khác biệt này là có ý nghĩa thống kê, $p<0,05$. Kết luận: CHT khuếch tán là kỹ thuật có giá trị trong dự đoán tính chất lành tính/ác tính của UMN trước phẫu thuât não,.

Tư khóa: cộng hưởng từ khuếch tán, u màng

${ }^{1}$ Bênh viên Đa khoa Hoàn Mỹ

2Viện Bỏng Quốc gia Lê Hữu Trác

33eệnh viện Quân y 103

Chịu trách nhiệm chính: Nguyễn Xuân Khái

Email: drxuankhai@gmail.com

Ngày nhận bài: 5.5.2021

Ngày phản biện khoa học: 24.6.2021

Ngày duyệt bài: 5.7.2021

\section{SUMMARY}

MAGNETIC RESONANCE IMAGING AND PATHOLOGICAL CORRELATES OF MENINGIOMAS

Objectives: To evaluate characteristics of meningiomas on magnetic resonance imaging in the differential diagnosis of benign and atypical/malignant meningiomas. Subjects and methods: crosssectional description, 73 patients diagnosed with the meningioma, had surgery and pathology results were meningioma at Viet Duc Hospital and 103 Military Hospital from October 2020 to March 2021. Results: $56 / 73$ cases were mostly benign; account for $76.7 \%$. Atypical and malignant meningiomas accounted for $23.3 \%$. Grade II atypical meningiomas had diffusion restriction on DWI, with $16 / 17$ tumors accounting for $94.1 \%$, while this rate in grade I menigiomas was $33.9 \%$. This difference was statistically significant, $p$ $<0.05$. Conclusion: diffusion-weighted was a valuable technique in predicting benign/malignant properties of meningiomas before surgery.

Keywords: diffusion-weighted magnetic resonance imaging, meningiomas.

\section{I. ĐĂT VẤN ĐỀ}

UMN là loại u xuất phát từ lớp màng não bao quanh não hoặc tủy sống, phân lớn là lành tính, là những khối u hay gặp sau u tế bào hình sao. Theo Black, tại Hoa Kỳ, UMN chiếm tỷ lệ khoảng 
$25 \%$ các khối u trong sọ, phổ biến nhất trong các loại u không phải tế bào hình sao [1]. Mặc dù đa số UMN là lành tính, tuy nhiên vẫn có tỷ lệ nhỏ ác tính. UMN ác tính thường có khuynh hướng xâm lấn và tái phát cao.

Kết quả mô bệnh học của UMN có ảnh hưởng lớn đến kế hoạch điều trị cũng như tiên lượng của bệnh nhân. Do đó, việc định hướng sớm tính chất lành tính/ác tính của UMN đóng vai trò quanh trọng trong thực hành lâm sàng. Hiện nay, trên thế giới có nhiều NC chỉ ra những đặc điểm hình ảnh $\mathrm{CHT}$ của UMN giúp phân biêt được giữa UMN lành tính và ác tính như: thoái hóa dạng nang, xâm lấn xương, xâm lấn mạch máu,...[2]. Tuy nhiên tại Việt Nam chưa có nhiều nghiên cứu về vấn đề này. Vì vậy, chúng tôi tiến hành NC này với mục tiêu: "Khảo sát mối liên quan giữa đặc điểm hình ảnh cộng hưởng từ và tính chất lành tính/ác tính của u màng não".

\section{II. ĐỐI TƯƠNG VÀ PHƯƠNG PHÁP NGHIÊN CỨU}

1. Đối tượng nghiên cứu: gồm 73 bệnh nhân với 73 khối u được chẩn đoán, phẫu thuật và có kết quả mô bệnh học là UMN tại khoa Phẫu thuật thần kinh, Bệnh viện Việt Đức và Bệnh viện Quân y 103 trong thời gian từ tháng 10/2020 đến tháng 03/2021.

2. Phương pháp nghiên cứu: Mô tả cắt ngang *Bênh nhân được chup $\mathrm{CHT}$ so não với các chuối xung axial và sagittal T1 FSE, axial T2 FSE, axial FLAIR, axial DWI, axial T2*, axial và coronal $\mathrm{T} 1$ GE sau tiêm đối quang từ (Gadolinium liều $0,1 \mathrm{mmol} / \mathrm{kg}$ cân nặng). Máy chụp là máy CHT 1,5 Tesla của hãng Philips.

*Các biến số dùng trong NC: đặc điểm hình ảnh khối u (tín hiệu trên hình ảnh T1, T2, và DWI, mức độ ngấm thuốc), kết quả giải phấu bệnh.

*Các tiêu chuẩn dùng trong NC:

- Tín hiệu tổn thương được lấy để mô tả là tín hiệu của vùng lớn nhất trong tổn thương và so với nhu mô não lân cận.

- Kết quả giải phấu bệnh được phân loại theo WHO 2010, chia thành 3 mức độ [3]: UMN lành tính (độ I), UMN không điển hình (độ II) và UMN thoái sản (độ III).

\section{KẾT QUẢ NGHIÊN CỨU}

1. Đặc điểm chung: Nghiên cứu trên 73 bênh nhẩn UMN, độ tuổi trung bình là $57,38 \pm$ 12,93 tuổi, đa số gặp ở BN nữ, tỷ lệ nữ/nam là $3,06 / 1$.

Bảng 6. Đặc điểm tín hiệu u trên CHT ( $n=73)$

\begin{tabular}{|c|c|c|c|}
\hline \multicolumn{2}{|c|}{ Đặc điểm tín hiệu } & $\mathbf{n}$ & $\%$ \\
\hline \multirow{2}{*}{ T1W } & Đồng tín hiệu & 46 & 63,0 \\
\cline { 2 - 4 } & Tăng tín hiệu & 0 & 0 \\
\hline
\end{tabular}

\begin{tabular}{|c|c|c|c|}
\hline & Giảm tín hiệu & 27 & 37,0 \\
\hline \multirow{3}{*}{$\mathrm{T} 2 \mathrm{~W}$} & Đồng tín hiệu & 20 & 27,4 \\
\hline & Tăng tín hiệu & 50 & 68,5 \\
\hline & Giảm tín hiệu & 3 & 4,1 \\
\hline \multirow[b]{2}{*}{ DWI/ADC } & Hạn chế khuếc tán & 35 & 47,9 \\
\hline & $\begin{array}{l}\text { Không hạn chế } \\
\text { khuếch tán }\end{array}$ & 38 & 52,1 \\
\hline \multirow{2}{*}{$\begin{array}{l}\text { T1W sau } \\
\text { tiêm }\end{array}$} & Ngấm thuốc đông nhất & 56 & 76,7 \\
\hline & $\begin{array}{l}\text { Ngấm thuốc không } \\
\text { đồng nhất }\end{array}$ & 17 & 23,3 \\
\hline
\end{tabular}

Nhận xét: Đa số UMN đồng tín hiệu trên hình ảnh $\mathrm{T} 1 \mathrm{~W}$, tăng tín hiệu trên hình ảnh T2W, lân lượt chiếm tỷ lệ $63,0 \%$ và $68,5 \%$. Có $35 / 73$ khối u có hạn chế khuếch tán chiếm tỷ lệ $47,9 \%$. Sau tiêm, hầu hết khối u ngấm thuốc đồng nhất, chiếm tỳ lệ 76,7\%. Không có khối u nào không ngấm thuốc.

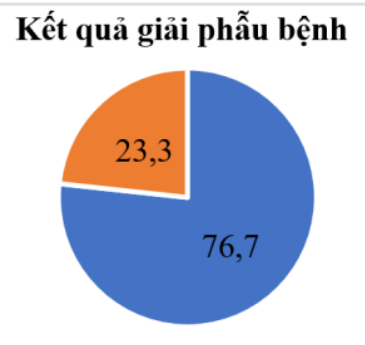

- UMN độ I " UMN độ II

Biểu đồ 2: Kêt quả giải phẫu bệnh $(n=73)$

Nhân xét: Đa số UMN trong nhóm NC là lành tính, chiếm tỷ lệ $76,7 \%$. UMN độ II chiếm tỷ lệ $23,3 \%$.

2. Mối liên quan giữa đăc điểm hình ảnh CHT và mô bênh học của UMN

Bảng 7: Môí liên quan giữa đặc điểm hình ảnh CHT và MBH của UMN ( $n=73)$

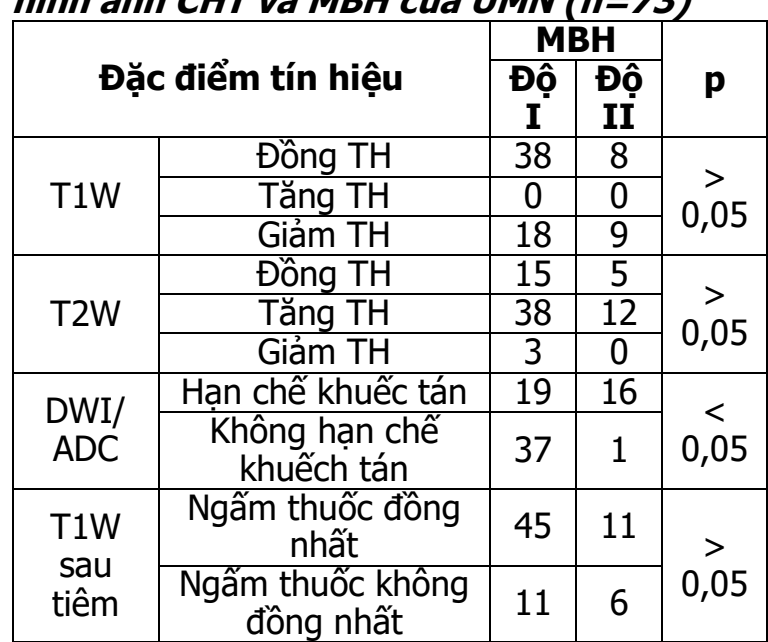

Nhận xét: Hầu hết UMN độ II có hạn chế khuếch tán trên DWI, với $16 / 17$ khối u chiếm tỷ lệ $94,1 \%$. Sự khác biệt này là có ý nghĩa thống 
kê $\mathrm{p}<0,05$.

Không thấy mối liên quan giữa đặc điểm tín hiệu trên hình ảnh $T 1$ và $T 2$ cũng như đặc điểm ngấm thuốc của khối u với mức độ lành tính/ác tính của UMN.

\section{BÀN LUÂ̂N}

Về đặc điểm chung. Đa số UMN đồng tín hiệu trên hình ảnh T1W, tăng tín hiệu trên hình ảnh T2W, lân lượt chiếm tỷ lệ $63,0 \%$ và $68,5 \%$. Kết quả này tướng tự với NC của Lê Thị Hồng Phương (2016): 61,4\% khối u đồng tín hiệu trên T1W, 70,2\% khối u tăng tín hiệu trên T2W [4]. UMN cấu tạo chủ yếu bởi chất xơ và hàm lượng nước thấp, do đó thường đồng tín hiệu trên T1W và tăng nhẹ tín hiệu trên $\mathrm{T} 2 \mathrm{~W}$. Điều này trái ngược với các u nội sọ khác, thường giảm tín hiệu vừa phải trên $T 1 W$, do tăng hàm lượng nước của các mô tân sinh [5]. UMN trên hình ảnh $\mathrm{CHT}$ trước tiêm ít đặc hiệu.

Trong nhóm NC, tỷ lệ u có hạn chế khuếch tán là 47,9\%. Theo Lê Thị Hồng Phương (2016), tỷ lệ UMN vùng nền sọ có hạn chế khuếch tán chiếm tỷ lệ 47,4\% [4]. Salah và cs (2019), có 29/71 khối u có hạn chế khuếch tán, chiếm tỷ lệ $40,8 \%$ [2]. Kết quả này tương đương với NC của chúng tôi.

Sau tiêm, hầu hết khối u ngấm thuốc đồng nhất, chiếm tỷ lệ $76,7 \%$. Không có khối u nào không ngấm thuốc. Zhang và cS (2018), tất cả khối u đều ngấm thuốc tương phản từ sau tiêm, trong đó có 38/142 khối u ngấm thuốc mạnh sau tiêm, chiếm tỷ lệ 26,8\% [6]. Các kết quả này tương đương với NC của chúng tôi. Hình ảnh CHT có tiêm thuốc giúp tăng khả năng phát hiện những khối u nhỏ, đồng tín hiệu với nhu mô nã̃o lân cận. Ngoài ra giúp đánh giá u tái phát hay còn sót sau phẫu thuật và giúp đánh giá tổn thương UMN dạng mảng.

Đa số UMN trong nhóm NC là lành tính, chiếm tỷ lệ $76,7 \%$. Lin và cs (2014) nghiên cứu trên 120 BN u màng não, có 90/120 BN u màng não độ thấp, chiếm tỷ lệ 75\% [7]. Kết quả này tương tự với nghiên cứu của chúng tôi. Những kết quả này cao hơn so với kết quả của chúng tôi. Như vậy, có thể u màng não vùng hố yên và trên yên có xu hướng lành tính hơn so với các vị trí khác.

Về mối liên quan giữa đặc điểm hình ảnh CHT và $M B H$ của UMN

Trên hình ảnh $T 1 W$ và $T 2 W$. Trong nghiên cứu của chúng tôi, không có mối liên hệ giữa đặc điểm tín hiệu trên hình ảnh T1W và T2W với kểt quả mô bệnh học, $\mathrm{p}>0,05$. Kết quả này tương tự với nghiên cứu của Lin và cộng sự (2014) [7]. Salah và cs (2019) nghiên cứu trên 71 BN u màng não, cũng không phát hiện mối liên quan giữa tín hiệu của u trên hình ảnh T1W, T2W và tính chất ác tính của u [2]. Hầu hết các tác giả đều đồng ý rằng, chỉ phân tích hình ảnh T1W không giúp định hướng typ mô bệnh học. Hình ảnh T2W có ý nghĩa hơn trong việc dự đoán tính chất lành tính/ác tính của u màng não. Các tác giả cho rằng u tăng tín hiệu trên $T 2$ có xu hướng là những u mềm, như u giàu mạch, u thể biểu mô. Còn những u có tín hiệu thấp trên T2W hầu hết là u thể xớ, có xu hướng cứng hơn so với các typ còn lại. Tuy nhiên, theo Salah (2019), không có mối liên quan giữa đăcc điểm hình ảnh T2W và mức độ ác tính của UMN [2]. Kết quả này tương đương với kết quả nghiên cứu của chúng tôi.

Trên hình ảnh DWI. Hầu hết UMN độ II có hạn chế khuếch tán trên DWI, với 16/17 khối u chiếm tỷ lệ $94,1 \%$. Sự khác biệt này là có ý nghĩa thống kê $p<0,05$. Theo Salah (2019), có 11/12 khối UMN độ II có hạn chế khuếch tán trên DWI, chiếm tỷ lệ $91,7 \%$. Cũng theo tác giả này, hình ảnh DWI có khả năng giúp phân biệt UMN lành tính và ác tính, sự khác biệt là có ý nghĩa thống kê, $p=0,07$ [2]. Nguyễn Thị Bảo Ngọc và cs (2013) NC trên 48 BN UMN cũng rút ra kết luận trên $\mathrm{CHT}$ khuếch tán, UMN không điển hình/ác tính có giá trị ADC thấp hơn đáng kể so với UMN lành tính, sự khác biệt là có ý nghĩa thống kê, $p<0,05$ [8]. Sohu và cs (2019) NC trên 152 khối UMN, rút ra kết luận, các khối UMN ác tính có tỷ lệ hạn chế khuếch tán trên DWI/ADC cao hơn so với các khối UMN lành tính, $p<0,001$ [9]. Các kết quả này tương tự kết quá NC của chúng tôi.

Trên hình ảnh T1 sau tiêm. Trong nghiên cứu của chúng tôi, không có mối liên quan giữa đặc điểm ngấm thuốc và tính chất lành tính/ác tính của u màng não, $p>0,05$. Theo nghiên cứu của Salah và cs (2019), có $73,9 \%$ tổng số u màng não độ ác cao ngấm thuốc không đồng nhất sau tiêm. Sự khác biệt về đặc điểm ngấm thuốc giữa nhóm lành tính và ác tính là có ý nghĩa thống kê, $p<0,001$ [2]. Trong nghiên cứu của Lin và CS (2014), tỷ lệ u màng não độ cao ngấm thuốc không đồng nhất là $43,3 \%$. Có mối liên quan giữa đặc điểm ngấm thuốc và mức độ lành tính/ác tính của khối u [7]. Các kết quả này khác với kết quả nghiên cứu của chúng tôi. Điều này có thể giải thích do cõ mẫu của chúng tôi chưa đủ lớn, chưa mang tính đại diện. Ngấm thuốc không đồng nhất trong u có thể giải thích 
do quá trình hoại tử u. Trong đó, cơ chế giải thích chính là cơ chế thiếu oxy gây nhồi máu trong $u$.

\section{KẾT LUÂ̂N}

Cộng hưởng từ thường quy với hình ảnh T1W, T2W và T1 sau tiêm không có giá trị trong phân biệt UMN lành/ác tính.

Trên hình ảnh DWI, UMN ác tính/không điển hình có tỷ lệ hạn chế khuếch tán nhiều hơn so với UMN lành tính. Do đó, $\mathrm{CHT}$ khuếch tán là xung có giá trị giúp dự đoán tính chất lành tính/ác tính của UMN trước phẫu thuật.

\section{TÀI LIỆ THAM KHẢO}

1. Elizabeth B. Claus, Melissa L. Bondy, Joellen M. Schildkraut. et al. (2005), "Epidemiology of Intracranial Meningioma". Neurosurgery, 57(6), pp. 1088-1095.

2. F. Salah, A. Tabbarah, N. Alarab y. et al. (2019), "Can CT and MRI features differentiate benign from malignant meningiomas?". Clinical Radiology, 74(11), pp. 898.e15-898.e23.
3. C. Mawrin,A. Perry (2010), "Pathological classification and molecular genetics of meningiomas". J Neurooncol, 99(3), pp. 379-91.

4. Lê Thị Hông Phương (2016). Đặc điểm hình ảnh cộng hưởng từ và mổi liên quan với triệu chứng lâm sàng của u màng não nền sọ. Luận văn tốt nghiệp Bác sĩ Nội trú, Đại học Y Hà Nội.

5. Antonios Drevelegas (2010), Imaging of brain tumors with histological correlations,Springer Science \& Business Media

6. T. Zhang, J. M. Yu, Y. Q. Wang. et al. (2018), "WHO grade I meningioma subtypes: MRI features and pathological analysis". Life Sci, 213, pp. 50-56.

7. B. J. Lin, K. N. Chou, H. W. Kao. et al. (2014) "Correlation between magnetic resonance imaging grading and pathological grading in meningioma". 1 Neurosurg, 121(5), pp. 1201-8.

8. Nguyến Thị Bảo Ngọc, Đặng Nguyễn Trung An, Trần Quang Vinhi. et àl. (2013), "Khảo sát đăc điểm hình ảnh cộng hưởng từ của u màng não nội sọ". Y học Thành phố Hồ Chí Minh, 17(1), pp. 500-503.

9. D. M. Sohu, S. Sohail,R. Shaikh (2019), "Diagnostic accuracy of diffusion weighted MRI in differentiating benign and malignant meningiomas". Pak J Med Sci, 35(3), pp. 726-730.

\title{
HIÊUU QUẢ CỦA DỤNG CỤ TỬ CUNG MIRENA TRONG ĐIỀU TRỊ MộT Số BÊ̂NH LÝ LÀNH TÍNH CỦA TỬ CUNG
}

\author{
Hà Duy Tiến ${ }^{1}$, Phạm Thị Tân ${ }^{1}$, Nguyễn Ngọc Phương ${ }^{1}$, \\ Phạm Thị Thanh Hiền ${ }^{2}$, Đào Văn Thụ ${ }^{1}$, Bùi Lê Khánh Chi ${ }^{1}$
}

\section{TÓM TẮT}

Mục tiêu: Nhận xét hiệu quả giảm đau và giảm ra máu của DCTC Mirena trong điều tri môt số bênh lý lành tính của tử cung. Đối tượng và phương pháp nghiên cứu: mô tả tiến cứu trên nhửng bệnh nhân có triệu chứng thống kinh và cường kinh được điều trị bằng DCTC Mirena, đánh giá hiệu quả sau 6 tháng sư dụng. Kết quả: Có 55 bệnh nhân được đặt DCTC Mirena để điêu trị, điểm đánh giá mức độ đau theo thang điểm VAS giảm từ 5,9 \pm 4,3 xuống 1,4 $\pm 2,4$, trong đó cải thiện rõ rệt ở nhóm đau khưng khiếp và đau nặng. Số ngày ra máu trung bình thay đổi không có ý nghĩa thống kê $(p=0,885)$, tuy nhiên tỷ lệ vô kinh tăng từ $3,6 \%$ lên $12,7 \%$ và ra máu kéo dài tăng từ $23,7 \%$ lên $40 \%$. Số lượng máu mất giảm đáng kể, đăc biệt ở nhóm ra máu nhiêu và trung binh. Kết luận: DCTC Mirena là phương pháp hiệu quả điều trị giảm đau và giảm ra máu trong các bệnh lý lành tính của tử cung.

\footnotetext{
${ }^{1}$ Bệnh viện Phụ Sản Trung Uơng

¿Đại họ Y Hà Nội

Chịu trách nhiệm chính: Nguyễn Ngọc Phương

Email: pika.hmu@gmail.com

Ngày nhận bài: 4.5.2021

Ngày phản biện khoa học: 25.6.2021

Ngày duyệt bài: 6.7.2021
}

Tư khóa: Dụng cụ tử cung (DCTC), Mirena, thống kinh, cường kinh.

\section{SUMMARY \\ THE EFFICACY OF MIRENA IN TREATMENT OF SOME BENIGN UTERINE DISEASES}

Objectives: To review the effects of the IUD Mirena in treatment of some benign uterine diseases, particularly in reducing menstrual blood loss and dysmenorrhea. Subjects and Methods: prospective description of patients with dysmenorrhea and menorrhagia treated with Mirena, and evaluation of results after 6 months of use. Results: 55 patients were inserted Mirena. The assessment score of pain on the VAS scale decreased from $5.9 \pm 4.3$ to $1.4 \pm$ 2.4 and a greater and more significant mean reduction occurred in the worst pain possible and very severe pain group. The mean number of bleeding days was not statistically significant $(p=0.885)$, but the rate of amenorrhea increased from $3.6 \%$ to $12.7 \%$, and prolonged bleeding rate increased from $23.7 \%$ to $40 \%$. The amount of blood loss decreased markedly, especially in the heavy and moderate bleeding groups. Conclusion: Mirena IUD is an effective treatment to alleviate the pain and reduce menstrual blood loss in some benign uterine diseases.

Keywords: Intrauterine device (IUD), Mirena, dysmenorrhea, menorrhagia. 